\title{
Effect of Zinc on the Growth and the Antioxidant System of Lens Culinaris Cultivated on Agar Medium
}

\author{
Asma Benhamdi ${ }^{*}$, Chouaib Kandouli', Radia Cherfia ${ }^{2}$, Soumia Chelouche ${ }^{1}$, \\ Zeinb Boumissa', Mohamed Elhadi Benniou', Roumeissa Hafdi', Aicha Mechakra' \\ 1 Biology and Environment Laboratory, Faculty of Nature and Life Sciences, University of frères Mentouri, \\ Constantine 1, Road Ain El Bey, Constantine 25017, Algeria \\ 2 Laboratory of Mycology, Biotechnology and Microbial Activity, University of frères Mentouri, Constantine 1, \\ Road Ain El Bey, Constantine 25017, Algeria \\ * Corresponding author's e-mail: asma.benhamdi@umc.edu.dz
}

\begin{abstract}
This study aimed to analyze the impact of $\mathrm{Zn}$ on the growth and the antioxidant response of Lens culinaris. For this purpose, the seeds were germinated for 6 days in an MS/2 culture medium with different $\mathrm{Zn}$ concentrations. Malondialdehyde (MDA), total protein contents, and antioxidant enzymes activities were measured in both parts of the plant by spectrometry. The results showed that from the $\mathrm{Zn}$ concentration of $250 \mu \mathrm{M}$, the growth of lentils is inversely proportional to the concentration of $\mathrm{Zn}$ in the culture medium. The variations in the level of MDA are not very significant, but at $10000 \mu \mathrm{M}$ of $\mathrm{Zn}$ in the medium, the level becomes very important, whilst the total protein content decreased. Besides, the evaluation of enzymatic activities indicated that the decline of peroxidase (POD) is concomitant with the increase in glutathione peroxidase (GPx) and that glutathione S-transferase (GST), as well as catalase (CAT) reach their maximum activities at $10000 \mu \mathrm{M}$ and $3000 \mu \mathrm{M}$ of $\mathrm{Zn}$ in upper parts and roots, respectively. These findings revealed that MDA is a real indicator of oxidative stress in Lens culinaris and that this plant is tolerant to the presence of $\mathrm{Zn}$ in the culture medium by developing a powerful antioxidant system, but beyond a certain concentration its antioxidant system becomes ineffective and the plant enters a stress state.
\end{abstract}

Keywords: growth, Lens culinaris, zinc, oxidative stress.

\section{INTRODUCTION}

The excessive use of heavy metals is one of the main sources of soil pollution. This is a result, to a great extent, of anthropocentric activities such as natural resource extraction (e.g. mining), toxic waste disposal, as well as agricultural use of herbicides and pesticides [Guan et al. 2014; Palm et al. 2017]. If certain oligo-elements (Fe, $\mathrm{Mn}, \mathrm{Zn}, \mathrm{Cu}, \mathrm{Mo}, \mathrm{Ni}$ ), present in trace amounts, are essential for plant growth and their absence will lead to slow growth and then cell death, the increase in their concentration is also toxic [Ying et al. 2019]. Zn acts as a cofactor for several enzymes and is necessary for various physiological processes such as protein synthesis, lipid, nucleic acid, and cell wall metabolism [Hajiboland, 2012;
Rai et al., 2021]. At high concentrations, $\mathrm{Zn}$ and $\mathrm{Cu}$ cause disruptions in many cellular processes, including growth and metabolism by inducing phytotoxicity [Ishimaru et al., 2011; Palm et al., 2017]. Besides, when plants are exposed to high levels of heavy metals, reactive oxygen species (ROS) are induced [Tamás et al., 2017]. In order to fight against these ROSs, plants activate different ROS-scavenging mechanisms. They are composed of both enzymatic systems (catalase (CAT), superoxide dismutase (SOD), peroxidase (POD), glutathione reductase (GR), glutathione S-transferase (GST), glutathione peroxidase (GPX), etc.) and non-enzymatic systems (glutathione (GSH), phytochelatins (PCs), ascorbate (AsA), proline (Pro), flavonoids, carotenoids,...) [Ahanger et al., 2015; Akram et al., 2017; Wei et 
al., 2020]. When the ROSs concentrations exceed the cellular detoxification capacity, the cell enters an oxidative stress state which translates into oxidative damage of lipidic membranes, DNA, and proteins; whereby their oxidation can lead to cell dysfunction [Valavanidis et al., 2006; Berni et al., 2019]. Lipid peroxidation occurs when the hydroxyl radical or singlet oxygen reacts with functional lipids that generate toxic aldehydes and ketones [Demidchik, 2015; Nanda and Agrawal, 2016]. Some plant species develop metal tolerance strategies which include exclusion strategies, detoxification and compartmentalization of metal ions inside the plant parts [DalCorso et al., 2013; Ovečka and Takáč, 2014]. The main objective of this investigation was to study, in vitro, the effect of zinc on the growth, the accumulation and the antioxidant responses of a Lens culinaris legume by evaluating, in the aerial parts and roots: the plant growth, the level of membrane lipoperoxidation (determined by the quantification of malondialdehyde "MDA") and the activities of antioxidant enzymes (glutathione S-tansferase GST, peroxidase POD, glutathione peroxidase GPX, and catalase CAT).

\section{MATERIAL AND METHODS}

The seeds of Lens culinaris were sterilized in bayrochloreat $1 \%$ for $30 \mathrm{~min}$ and then rinsed thoroughly with sterile distilled water. They were then germinated in Petri dishes containing a filter paper soaked in sterile ultrapure water for 24 hours in the dark at $4{ }^{\circ} \mathrm{C}$ and then transferred to individual plastic pots containing the solid MS/2 medium [Murashige and Skoog, 1962] treated with $\mathrm{ZnSO}_{4}(0 \mu \mathrm{M}, 250 \mu \mathrm{M}, 750 \mu \mathrm{M}, 3000 \mu \mathrm{M}$, $5000 \mu \mathrm{M}$, and $10000 \mu \mathrm{M})$ at a rate of 6 seeds per pot for each concentration. They were then placed in the culture chamber at $22^{\circ} \mathrm{C}$, with a photoperiod of $16 \mathrm{~h}$ per day for 7 days.

\section{Preparation of crude extract}

After the germination of the seeds, the roots and the aerial parts were weighed separately and then crushed, under liquid nitrogen, with a mortar using a phosphate buffer solution $(0.1 \mathrm{M}, \mathrm{pH}=7.6)$ containing $0.1 \%$ Triton $\mathrm{X}-100,1 \%$ Polyvinylpyrrolidone (PVP) and ETDA $(1 \mathrm{mM})$. The homogenate was centrifuged at $4{ }^{\circ} \mathrm{C}$ for $15 \mathrm{~min}$ at $12000 \mathrm{~g}$.

\section{MDA Contents and antioxidant Enzymes Activities}

The level of oxidative stress was evaluated throughthe determination of the MDA amount according to the method of [Kosugi and Kikugawa, 1985]. The principle of the assay is based on the reaction produced between malondialdehyde and thiobarbituric acid (TBA) forming the colored derivative MDA-TBA2 absorbing at $532 \mathrm{~nm}$. The results were expressed as $\mu \mathrm{mol}$ MDA formed $\mathrm{g}$ tissue ${ }^{-1}$ by using a molar extinction coefficient of $155 \mathrm{mM}^{-1} \mathrm{~cm}^{-1}$.

The peroxidase activity is performed according to the method of [Chance and Machly, 1967]. The content of purpurogallin formed between $\mathrm{H}_{2} \mathrm{O}_{2}$ and pyrogallol, by the action of peroxidase, is determined by measuring the absorbance at $420 \mathrm{~nm}$ against a blank. It is expressed in units $=0.1$ absorbance $\mathrm{min}^{-1} \mathrm{mg}^{-1}$ of protein. The glutathione peroxidase (GSH-Px) activity is determined according to the method of [Flohé and Günzler, 1984]. It is based on the reduction of hydrogen peroxide $\mathrm{H}_{2} \mathrm{O}_{2}$ in the presence of reduced glutathione (GSH). The latter is transformed into glutathione disulfide (GSSG) under the influence of GSH-Px. The reaction is stopped by adding a strong acid, whereby the remaining GSH content is measured spectrophotometrically at $412 \mathrm{~nm}$. It is expressed in $\mu$ mol GSH mg-1 of protein. Moreover, the measurement of catalase activity is carried out according to the method of [Chance and Maehly, 1955]. The decomposition of hydrogen peroxide is determined by the decrease in absorbance at $240 \mathrm{~nm}\left(\mathrm{e}=39.4 \mathrm{mM}^{-1}\right.$ $\mathrm{cm}^{-1}$ ). Additionally, the evaluation of glutathione S-transferase activities is carried out according to the method of [Habig and Jakoby, 1981], in which the principle is based on the measurement of the absorbance at $340 \mathrm{~nm}$ of the Glutathione-2,4-Dinitrobenzene complex formed between GSH and CDNB by the action of GST $\left(\varepsilon=9.6 \mathrm{mM}^{-1}\right)$. The protein concentrations are quantified according to the method of [Lowry et al., 1951]. BSA is used as a standard protein.

\section{STATISTICAL ANALYSES}

The statistical tests performed during this study are the mean $\pm \mathrm{SD}(\mathrm{N}=3)$ and the analysis of the variance (ANOVA) followed by the Tukey test. The variance analysis was conducted 
to compare the different classes of $\mathrm{Zn}$ concentrations of each part (aerial and root) compared to the class of plant witnesses. The results are treated using the software: Excel 2007 and XLSTAT 2016 with a significance level of 0.05 .

\section{RESULTS}

\section{Plant Growth}

The results revealed that the lentil growth reaches its maximum and even exceeds that of witnesses at a $\mathrm{Zn}$ concentration of $250 \mu \mathrm{M}$ in both parts of the plant (Fig. 1). Beyond this concentration, the growth becomes inversely proportional to the concentration of $\mathrm{Zn}$ in the culture medium.

\section{MDA content}

The MDA level is higher in the root parts (Fig. 2b). Whereby, till $5000 \mu \mathrm{M}$ concentration of $\mathrm{Zn}$ in the culture medium, the variations in
MDA content in the roots are very weakly significant compared to that in witnesses plants and they are almost stable in the upper parts. However, when the concentration of zinc in the medium reaches $10000 \mu \mathrm{M}$, the MDA content is significantly high in both parts of the plant compared to that of plant control $(\mathrm{p}<0.05)$.

\section{Total Proteins content and antioxidant enzymes activities}

The finding of the present study exhibited that in the presence of zinc, the activities of antioxidant enzymes are higher in the roots and differ from one zinc concentration to another in both parts of the plant (Fig. 2). For total proteins, their concentration is higher in the aerial parts, whereby the high concentration of $\mathrm{Zn}$ decreased the total proteins content (Fig. 2a). Besides, the evaluation of enzymatic activities indicates that the decline in the POD activity (Fig. 2c) is concomitant with the increase in that of GPx (Fig. 2d). Furthermore, the GPX activity
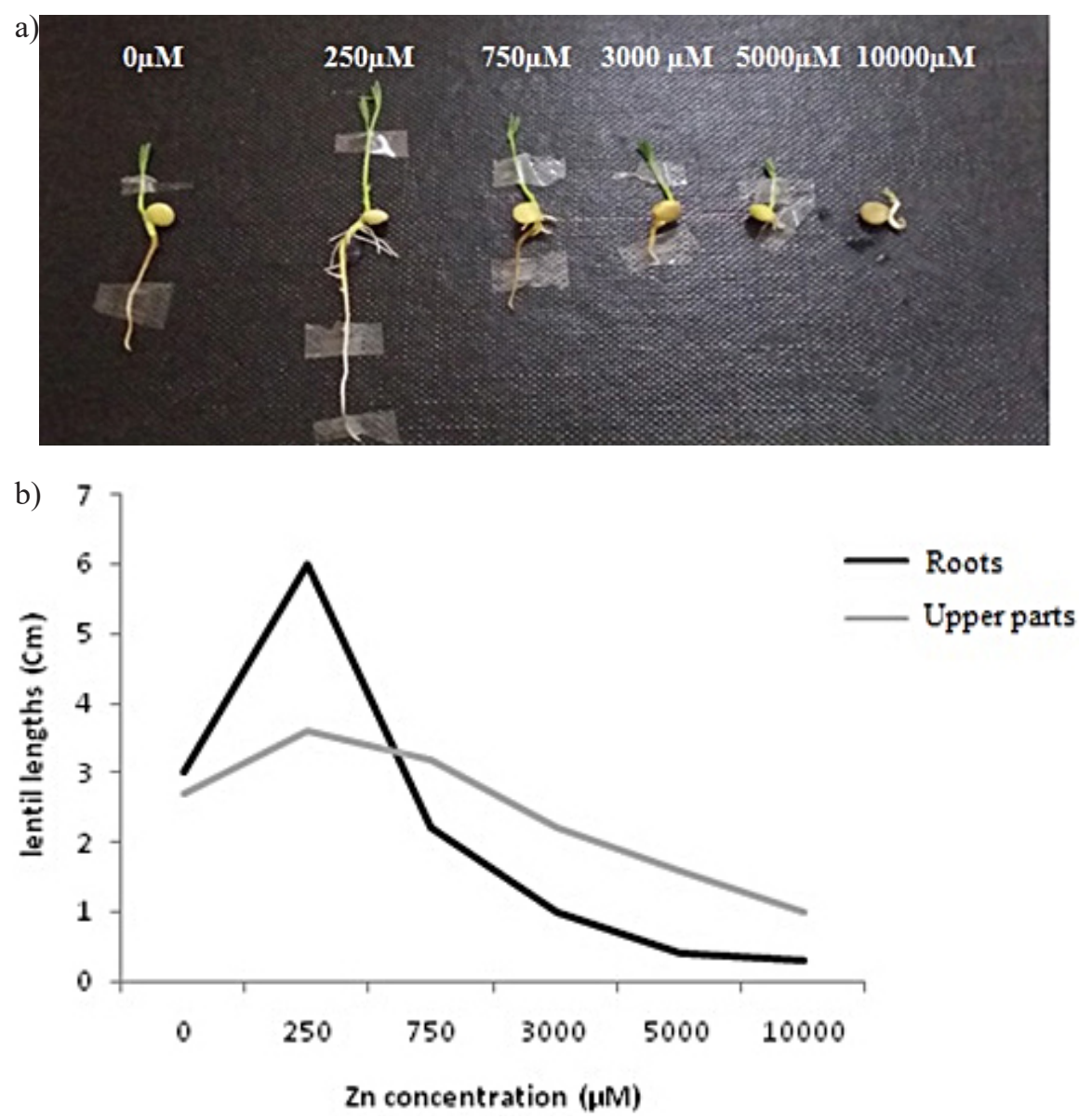

Figure 1. Effect of $\mathrm{Zn}$ on the growth of Lens culinaris after 6 days; a) Morphological phenotype; b) Lengths of aerial parts and roots 

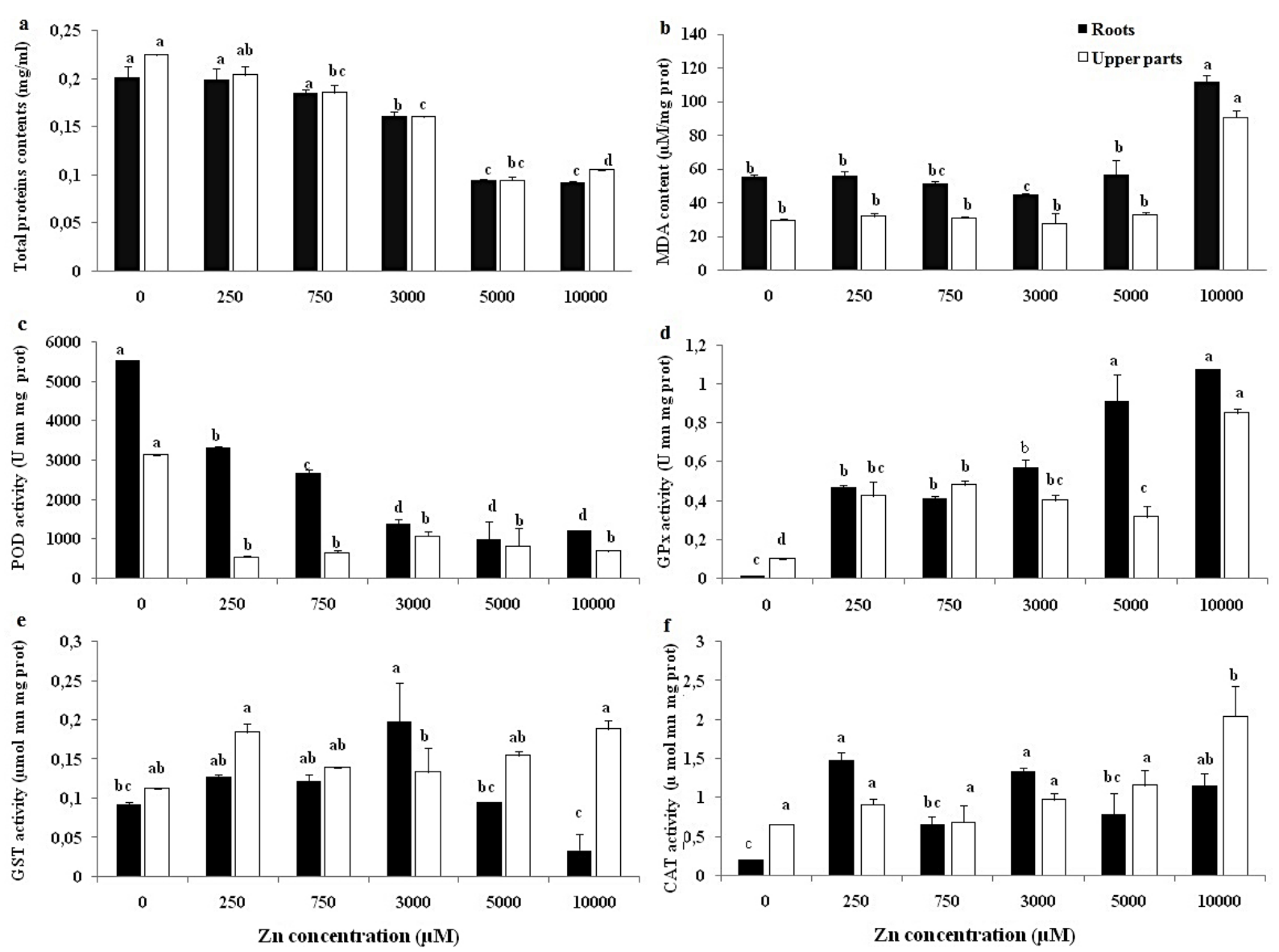

Figure 2. Biochemical responses in the upper parts and the roots of Lens culinaris. The seeds were germinated for 6 days on an MS/2 culture medium with different Zn concentrations $(0 \mu \mathrm{M}, 250 \mu \mathrm{M}, 750 \mu \mathrm{M}, 3000 \mu \mathrm{M}, 5000$ $\mu \mathrm{M}$, and $10000 \mu \mathrm{M})$. The total proteins contents (a), the MDA (b), and the activities of POD (c), GPx (d), CAT (e) and GST (f) were measured; respectively. Values represent means $\pm \mathrm{SD}(\mathrm{N}=3)$. Different letters discriminate statistical differences between the corresponding zones of the same plant part (using ANOVA followed by HSD test from Tukey, $\mathrm{p}<0.05$ )

reaches its maximal at $10000 \mu \mathrm{M}$ of $\mathrm{Zn}$ in both parts of the plant whereas that of POD is very low compared to that of witnesses plants at the same concentration. Figure 2 shows that POD represents a great activity in the roots; however, it is decreased significantly in both parts of the plant compared to that of plant controls; till the concentration of $10000 \mu \mathrm{M}$ in $\mathrm{Zn}$. The variation in the GPX activity depends on the rising of $\mathrm{Zn}$ concentrations. It increases significantly in both parts of the plant and the maximum activities are observed at $10000 \mu \mathrm{M}$ (Fig. 2). The CAT activity increases in both parts of the plant at $250 \mu \mathrm{M}$ and then decreases at $750 \mu \mathrm{M}$ compared to the previous class (Fig. 2f). The latter then increases again very significantly at 3000 , 5000 , and $10000 \mu \mathrm{M}$ of $\mathrm{Zn}$ in the aerial parts. The GST activity in the roots reaches its maximum at $3000 \mu \mathrm{M}$ and then decreases to reach the minimum activity at $10000 \mu \mathrm{M}$ of $\mathrm{Zn}$ in the culture medium. In the aerial parts, the activity is always significantly high compared to that of the plant controls and reached its maximum at 250 and $10000 \mu \mathrm{M}$ concentrations of $\mathrm{Zn}$ in the culture medium (Fig. 2e).

\section{DISCUSSION}

$\mathrm{Zn}$ is the most abundant transition metal after iron. It acts as a nutrient for plants and is involved in various biochemical and physiological reactions [Zeng et al., 2021], such as phytohormone activity, protein synthesis, photosynthesis, carbohydrate metabolism, cell defense... [Sadeghzadeh, 2013]. The study of the Lens culinaris growth shows that this plant tolerates high concentrations of zinc in the culture medium. The increase in growth of the aerial parts and roots observed at the $250 \mu \mathrm{M}$ concentration can be attributed to the 
fact that $\mathrm{Zn}$ maintains its role as an oligo-element. The reduction in the length of the aerial parts and roots of plants, at a concentration greater than $250 \mu \mathrm{M}$ of $\mathrm{Zn}$, may be caused by a progressive reduction in the number of cells. The reduction in plant length at a higher concentration of heavy metals was also observed in tomato plants(zinc) [Vijayarengan and Mahalakshmi, 2013], maize $\left(\mathrm{Cd}^{2+}, \mathrm{Ni}^{2+}, \mathrm{Cu}^{2+}\right.$, and $\mathrm{Zn}^{2+}$ ) [AbdElgawad et al., 2020] and sunflower seeds $\left(\mathrm{Cd}^{2+}, \mathrm{Ni}^{2+}, \mathrm{Pb}^{2+}\right.$, and $\mathrm{Zn}^{2+}$ )[Zhao et al., 2021]. High concentrations of $\mathrm{Zn}$ in soils show severe toxicity symptoms in plants and lead to a reduction in photosynthesis, delay in growth, and disturbance in absorption of other nutrients. The induction of ROS production is the major deleterious effect of zinc toxicity in plant cells [Goodarzi et al., 2020]. It has been accepted that MDA is a major biochemical marker of peroxidative damage to biological membranes and an indicator for oxidative stress induced cell damages [Hu et al., 2012; Pandian et al., 2020; Kulbat-Warycha et al., 2020]. The obtained results revealed that lipid peroxidation was almost stable till the concentration of $5000 \mu \mathrm{M}$ of zinc. This may be due to the fact that the plant has developed a powerful enzymatic and non-enzymatic antioxidant system acting in a coordinated way to control the normal intercellular ROS steady-state level and in maintaining the balance between ROS production and scavenging [Halliwell and Gutteridge, 2015; Esposito et al., 2018]. The rapid increase in the MDA level at a concentration of $10000 \mu \mathrm{M}$ in zinc translated into the inability of the antioxidant system and by the disequilibrium in the oxidant-antioxidant balance in favor of ROS [Malod et al., 2020]. MDA contents increased at high concentrations of $\mathrm{Zn}$, whilst the total proteins contents decreased. These results are in agreement with those observed in oregano plants where the total protein content decreased with increasing concentration of $\mathrm{Ni}$ and $\mathrm{Zn}$ in the soil and the significantly higher MDA content was noticed at the highest concentration of those metals [Kulbat-Warycha et al., 2020]. Moreover, under the influence of heavy metals, the expression of proteins that are involved in cell signaling, stress detoxification, growth development, and protein biosynthesis are affected and the generated ROS denature several proteins involved in the central metabolic pathway [Cherrad et al., 2012; Shahzad et al., 2018; Rai et al., 2021]. When a metal is present, antioxidant enzymes are thought to be essential in the detoxification of toxic oxygen species produced preventing membrane lipid peroxidation and the production of MDA [Xu et al., 2021; Sharma et al., 2021]. For example, anions of hydrogen peroxide can be converted to radical oxygen and then to $\mathrm{O}_{2}$ and $\mathrm{H}_{2} \mathrm{O}$ at ground level [Sharma et al., 2021]. The increase of CAT activity following the treatment of the medium by $\mathrm{Zn}$ is due to the high production of ROS. These findings are similar to those observed in the aerial parts of Brassica juncea in the presence of Zn [Prasad et al., 1999] and in Ranunculus sceleratus, Rumex dentatus, and Cammelina benghalensis in the presence of Cd [Sharma et al., 2021] where the CAT activity was significantly stimulated. Whereby, the results of the GST activity, in the upper parts, are similar to those of CAT. The GST, which plays a key role in cellular protection against heavy metals and ROS [Park et al., 2020; Helaoui et al., 2020] is responsible for the detoxification of xenobiotic and endobiotic compounds [Ahmadi et al., 2021] by covalent binding of glutathione (GSH) to a hydrophobic substrate and consequently, a less reactive conjugate glutathione S-R is formed [Mohsenzadeh et al., 2009]. This enzyme is defined as a biomarker of contamination by the ETM [Hou et al., 2019]. The increase in the GST activity, in response to metallic stress, has been previously reported in the colza plants exposed to different concentrations of zinc [Wang et al., 2009], in Hedysarum pallidum in the presence of antimony [Benhamdi et al., 2014], in Medicago sativa exposed to Ni [Helaoui et al., 2020] and in Cichorium intybus $L$ in presence of $\mathrm{Pb}$ and $\mathrm{Al}$ [Malik et al., 2021]. The POD which reduces $\mathrm{H}_{2} \mathrm{O}_{2}$ using several reductants of phenolic compounds [Lamhamdi et al., 2011] is one of the antioxidant enzymes involved in scavenging ROS in plants [Lin et al., 2016; Jośko et al., 2021], it participates in several biological processes such as cell formation, auxin catabolism, lignifications, defense against stress, etc. [Bhaduri and Fulekar, 2012]. The decrease in the POD activity resulting from the $\mathrm{Zn}$ treatments identified in this study can be explained by the inhibitory effect of this latter. It was observed in the leaf tissues of Cichorium intybus wheat treated with different concentrations of Ni [Pandey and Sharma, 2002] and in Zea mays treated with SbIII [Pan et al., 2011]. Zhang et al., [2015] reported that the excessive production of ROS may decrease the level of antioxidants. Moreover, antioxidant enzymes may be inhibited by a heavy metal via metal interaction with the sulfhydryl group or other functional groups. This 
decline in POD is concomitant with the increase in GPx. GPx is considered also to be a powerful ROS scavenger by its wider substrate specifications and strong affinity for $\mathrm{H}_{2}-\mathrm{O}_{2}-$ [Bernard et al., 2015; Zouari et al., 2016]. The high activity of the GPX in the roots of lentils is due to the fact that the stress level, induced by $\mathrm{Zn}$, is higher in this part. This is confirmed by the MDA content which is very high at the root level. Similarly, the increase in its activity, following metal stress, has been observed in several plants such as Zostera japonica [Lin et al., 2016], Phoenix dactylifera L.[Zouari et al., 2016], and Oryza sativa L [Ranjan et al., 2021] treated with $\mathrm{Cu}, \mathrm{Cd}$ and $\mathrm{As}$, respectively.

\section{CONCLUSIONS}

The evaluation of MDA and protein contents, as well as the enzymatic activities in Lens culinaris, in addition to the results of previous works carried out on the mechanism of absorption, growth, and antioxidant defense in plants, make it possible to propose a mechanism of Lens culinaris tolerance to $\mathrm{Zn}$ in the culture medium. Lentil is a plant tolerant to the presence of $\mathrm{Zn}$ in the culture medium which acts as an oligo-element and is absorbed by the roots of the lentils. At a concentration greater than $250 \mu \mathrm{M}$ of $\mathrm{Zn}$ in the culture medium, the plant begins to induce the production of ROSs which causes several cellular damages; the first damaged site is the plasma membrane, because ROSs attack its polyunsaturated fatty acids by producing MDA. In addition, the $\mathrm{Zn}$ molecules can bind to the thiol groups of certain proteins and enzymes by inactivating and inhibiting them. This translates into a decrease in protein levels in lentils. Till $5000 \mu \mathrm{M}$ of $\mathrm{Zn}$, the stability of the MDA level shows that the antioxidant system of the lentil has been able to minimize the effects of ROS by transforming them into non-radical molecules. The increase in the CAT activity (which ensures the dismutation of $\mathrm{H}_{2} \mathrm{O}_{2}$ ), in the GST (which acts against the ROS and sequesters the $\mathrm{Zn}$ at the level of vacuoles), and in the GPX (which ensures the dismutation of $\mathrm{H}_{2} \mathrm{O}_{2}$ ) confirms that the antioxidant system of lentil is active. The POD is also a part of the antioxidant system but its activity is inhibited by $\mathrm{Zn}$, where its level decreases. At the concentration of $\mathrm{Zn}$ amounting to $100000 \mu \mathrm{M}$, the very rapid and significant increase in the level of MDA shows that plants enter a stress state and that the antioxidant system is depleted as a whole, despite the increased activity of CAT, GPX, and GST. Thus, stress occurs when the balance between the production of free radicals and their physiological destruction is positive.

\section{Acknowledgements}

This work was supported by the Algerian Ministry of Higher Education and Scientific Research. The authors are grateful to the technicians from the biochemistry laboratory, of the faculty of natural and life Sciences from University of frères Mentouri, Constantine 1, for their assistance to carry out this work.

\section{REFERENCES}

1. AbdElgawad H., Zinta G., Hamed B.A., Selim S., Beemster G., Hozzein W.N., Wadaan M.A., Asard H., Abuelsoud W. 2020. Maize roots and shoots show distinct profiles of oxidative stress and antioxidant defense under heavy metal toxicity. Environmental Pollution, 258, 113705.

2. Ahanger M.A., Agarwal R.M., Tomar N.S., Shrivastava M. 2015. Potassium induces positive changes in nitrogen metabolism and antioxidant system of oat (Avena sativa L cultivar Kent). Journal of plant interactions, 10(1), 211-223.

3. Ahmadi S., Ghafouri H., Tarazi S., Sarikhan S., Kh O.S. 2021. Cloning purification and biochemical characterization of two glutathione S-transferase isoforms from Rutilus frisii kutum. Protein Expression and Purification, 179, 105800.

4. Akram N.A., Shafiq F., Ashraf M. 2017. Ascorbic acid-a potential oxidant scavenger and its role in plant development and abiotic stress tolerance. Frontiers in plant science, 8, 613.

5. Benhamdi A., Bentellis A., Rached O., Du Laing G., Mechakra A. 2014. Effects of Antimony and Arsenic on Antioxidant Enzyme Activities of Two Steppic Plant Species in an Old Antimony Mining Area. Biological trace element research, 158, 96-104.

6. Bernard F., Brulle F., Dumez S., Lemiere S., Platel A., Nesslany F., Cuny D., Deram A., Vandenbulcke F. 2015. Antioxidant responses of Annelids Brassicaceae and Fabaceae to pollutants: a review. Ecotoxicology and environmental safety, 114, 273-303.

7. Berni R., Luyckx M., Xu X., Legay S., Sergeant K., Hausman J.F., Lutts S., Cai G., Guerriero G. 2019. Reactive oxygen species and heavy metal stress in plants: Impact on the cell wall and secondary metabolism. Environmental and Experimental Botany, 161, 98-106. 
8. Bhaduri A.M., Fulekar M.H., 2012. Antioxidant enzyme responses of plants to heavy metal stress. Reviews in Environmental Science and Bio/Technology, 11, 55-69.

9. Chance B., Machly A. 1967. Methods of biochemical analysis in: Interscience Publishers Inc. Glick D New York.

10. Chance B., Maehly A.C. 1955. [136] Assay of catalases and peroxidases. Methods in enzymology, 2, 764-775.

11. Cherrad S., Girard V., Dieryckx C., Gonçalves I.R., Dupuy J.-W., Bonneu M., Rascle C., Job C., Job D., Vacher S. 2012. Proteomic analysis of proteins secreted by Botrytis cinerea in response to heavy metal toxicity. Metallomics, 4(8), 835-846.

12. DalCorso G., Manara A., Furini A. 2013. An overview of heavy metal challenge in plants: from roots to shoots. Metallomics, 5(9), 1117-1132.

13. Demidchik V. 2015. Mechanisms of oxidative stress in plants: from classical chemistry to cell biology. Environmental and experimental botany, 109, 212-228.

14. Esposito M.P., Nakazato R.K., Pedroso A.N.V., Lima M.E.L., Figueiredo M.A., Diniz A.P., Kozovits A.R., Domingos M. 2018. Oxidant-antioxidant balance and tolerance against oxidative stress in pioneer and non-pioneer tree species from the remaining Atlantic Forest. Science of the Total Environment, 625, 382-393.

15. Flohé L., Günzler W.A. 1984. Assays of glutathione peroxidase. Methods in enzymology, 105, 114-120.

16. Goodarzi A., Namdjoyan S., Soorki A.A. 2020. Effects of exogenous melatonin and glutathione on zinc toxicity in safflower (Carthamus tinctorius L.) seedlings. Ecotoxicology and environmental safety, 201, 110853.

17. Guan Y., Shao C., Ju M. 2014. Heavy metal contamination assessment and partition for industrial and mining gathering areas. International journal of environmental research and public health, 11(7), 7286-7303.

18. Habig W.H., Jakoby W.B. 1981. Assays for differentiation of glutathione S-transferases. Methods in enzymology, 77, 398.

19. Hajiboland R. 2012. Effect of micronutrient deficiencies on plants stress responses in: Abiotic Stress Responses in Plants. Springer, 283-329.

20. Halliwell B., Gutteridge J.M. 2015. Free radicals in biology and medicine. Oxford University Press USA.

21. Hartikainen H., Xue T., Piironen V. 2000. Selenium as an anti-oxidant and pro-oxidant in ryegrass. Plant and soil, 225, 193-200.

22. Helaoui S., Boughattas I., Hattab S., Mkhinini M., Alphonse V., Livet A., Bousserrhine N., Banni M. 2020. Physiological biochemical and transcriptomic responses of Medicago sativa to nickel exposure. Chemosphere, 249, 126121.
23. Hou X., Tan L., Tang S.F. 2019. Molecular mechanism study on the interactions of cadmium (II) ions with Arabidopsis thaliana glutathione transferase Phi8. Spectrochimica Acta Part A: Molecular and Biomolecular Spectroscopy, 216, 411-417.

24. Ishimaru Y., Bashir K., Nishizawa N.K. 2011. Zn uptake and translocation in rice plants. Rice, 4, 21-27.

25. Jośko I., Kusiak M., Oleszczuk P., Świeca M., Kończak M., Sikora M. 2021. Transcriptional and biochemical response of barley to co-exposure of metal-based nanoparticles. Science of The Total Environment, 782, 146883.

26. Kosugi H., Kikugawa K. 1985. Thiobarbituric acid reaction of aldehydes and oxidized lipids in glacial acetic acid. Lipids, 20, 915-921.

27. Kulbat-Warycha K., Georgiadou E.C., Mańkowska D., Smolińska B., Fotopoulos V., Leszczyńska J. 2020. Response to stress and allergen production caused by metal ions ( $\mathrm{Ni} \mathrm{Cu}$ and $\mathrm{Zn}$ ) in oregano (Origanum vulgare L.) plants. Journal of Biotechnology, 324, 171-182.

28. Lamhamdi M., Bakrim A., Aarab A., Lafont R., Sayah F. 2011. Lead phytotoxicity on wheat $(<$ i $>$ Triticum aestivum L. $</$ i $>$ ) seed germination and seedlings growth. Comptes rendus biologies, 334(2), 118-126.

29. Lin H., Sun T., Zhou Y., Zhang X. 2016. Anti-oxidative feedback and biomarkers in the intertidal seagrass Zostera japonica induced by exposure to copper lead and cadmium. Marine pollution bulletin, 109(1), 325-333.

30. Lowry O.H., Rosebrough N.J., Farr A.L., Randall R.J. 1951. Protein measurement with the Folin phenol reagent. Journal of biological chemistry, 193, 265-275.

31. Malik B., Pirzadah T.B., Tahir I., Hakeem K.R., Rather I.A., Sabir J.S., Rehman R.U. 2021. Lead and aluminium-induced oxidative stress and alteration in the activities of antioxidant enzymes in chicory plants. Scientia Horticulturae, 278, 109847.

32. Malod K., Roets P.D., Oosthuizen C., Blount J.D., Archer C.R., Weldon C.W. 2020. Selection on age of female reproduction in the marula fruit fly Ceratitis cosyra (Walker)(Diptera: Tephritidae) decreases total antioxidant capacity and lipid peroxidation. Journal of Insect Physiology, 125, 104084.

33. Mohsenzadeh S., Saffari B., Mohabatkar H. 2009. A new member of Tau-class glutathione S-transferase from barley leaves. Excli Journal, 8, 190-194.

34. Murashige T., Skoog F. 1962. A revised medium for rapid growth and bio assays with tobacco tissue cultures. Physiologia plantarum, 15, 473-497.

35. Nanda R., Agrawal V. 2016. Elucidation of zinc and copper induced oxidative stress DNA damage and activation of defence system during seed germination in Cassia angustifolia Vahl. Environmental and Experimental Botany, 125, 31-41. 
36. Ovečka M., Takáč T. 2014. Managing heavy metal toxicity stress in plants: biological and biotechnological tools. Biotechnology Advances, 32(1), 73-86.

37. Palm E., Nissim W.G., Giordano C., Mancuso S., Azzarello E. 2017. Root potassium and hydrogen flux rates as potential indicators of plant response to zinc copper and nickel stress. Environmental and Experimental Botany, 143, 38-50.

38. Pan X., Zhang D., Chen X., Bao A., Li L. 2011. Antimony accumulation growth performance antioxidant defense system and photosynthesis of Zea mays in response to antimony pollution in soil. Water Air \& Soil Pollution, 215, 517-523.

39. Pandey N., Sharma C.P. 2002. Effect of heavy metals $\mathrm{Co}<\sup >2+</ \sup >\mathrm{Ni}<\sup >2+</$ sup $>$ and $\mathrm{Cd}<\sup >2+</$ sup $>$ on growth and metabolism of cabbage. Plant Science, 163(4), 753-758.

40. Pandian S., Rakkammal K., Rathinapriya P., Rency A.S., Satish L., Ramesh M. 2020. Physiological and biochemical changes in sorghum under combined heavy metal stress: An adaptive defence against oxidative stress. Biocatalysis and Agricultural Biotechnology, 29, 101830.

41. Park J.C., Hagiwara A., Park H.G., Lee J.S. 2020. The glutathione S-transferase genes in marine rotifers and copepods: Identification of GSTs and applications for ecotoxicological studies. Marine Pollution Bulletin, 156, 111080.

42. Prasad K., Saradhi P.P., Sharmila P. 1999. Concerted action of antioxidant enzymes and curtailed growth under zinc toxicity in Brassica juncea. Environmental and experimental Botany, 42(1), 1-10.

43. Rai K.K., Pandey N., Meena R.P., Rai S.P. 2021. Biotechnological strategies for enhancing heavy metal tolerance in neglected and underutilized legume crops: A comprehensive review. Ecotoxicology and Environmental Safety, 208, 111750.

44. Rai S., Singh P.K., Mankotia S., Swain J., Satbhai S.B. 2021. Iron Homeostasis in Plants and its Crosstalk with Copper Zinc and Manganese. Plant Stress, 100008.

45. Ranjan R., Kumar N., Gautam A., Dubey A.K., Pandey S.N., Mallick S. 2021. Chlorella sp. modulates the glutathione mediated detoxification and S-adenosylmethionine dependent methyltransferase to counter arsenic toxicity in Oryza sativa L. Ecotoxicology and Environmental Safety, 208, 111418.

46. Sadeghzadeh B. 2013. A review of zinc nutrition and plant breeding. Journal of soil science and plant nutrition, 13(4), 905-927.

47. Shahzad B., Tanveer M., Che Z., Rehman A., Cheema S.A., Sharma A., Song H., ur Rehman S., Zhaorong D. 2018. Role of 24-epibrassinolide (EBL) in mediating heavy metal and pesticide induced oxidative stress in plants: a review. Ecotoxicology and environmental safety, 147, 935-944.
48. Sharma P., Tripathi S., Sirohi R., Kim S.H., Ngo H.H., Pandey A. 2021. Uptake and mobilization of heavy metals through phytoremediation process from native plants species growing on complex pollutants: Antioxidant enzymes and photosynthetic pigments response. Environmental Technology \& Innovation, 101629.

49. Tamás L., Mistrík I., Zelinová V. 2017. Heavy metal-induced reactive oxygen species and cell death in barley root tip. Environmental and Experimental Botany, 140, 34-40.

50. Valavanidis A., Vlahogianni T., Dassenakis M., Scoullos M. 2006. Molecular biomarkers of oxidative stress in aquatic organisms in relation to toxic environmental pollutants. Ecotoxicology and environmental safety, 64(2), 178-189.

51. Vijayarengan P., Mahalakshmi G. 2013. Zinc toxicity in tomato plants. World Applied Sciences Journal 24(5), 649-653.

52. Wang C., Zhang S.H., Wang P.F., Hou J., Zhang W.J., Li W., Lin Z.P. 2009. The effect of excess Zn on mineral nutrition and antioxidative response in rapeseed seedlings. Chemosphere, 75(11), 1468-1476.

53. Wei L., Zhang J., Wang C., Liao W. 2020. Recent progress in the knowledge on the alleviating effect of nitric oxide on heavy metal stress in plants. Plant Physiology and Biochemistry, 147, 161-171.

54. Xu Z., Yang Z., Shu W., Zhu T. 2021. Combined toxicity of soil antimony and cadmium on earthworm Eisenia fetida: Accumulation biomarker responses and joint effect. Journal of Hazardous Materials Letters, 2, 100018.

55. Ying M., Yasuda H., Kobayashi S., Sakurai N., Kidou S. 2019. Barley cold-induced CISP proteins contribute to the accumulation of heavy metals in roots. Environmental and Experimental Botany, 165, 53-58.

56. Zeng H., Wu H., Yan F., Yi K., Zhu Y. 2021. Molecular regulation of zinc deficiency responses in plants. Journal of Plant Physiology, 153419.

57. Zhang Q., Zeng G., Chen G., Yan M., Chen A., Du J., Huang J., Yi B., Zhou Y., He X. 2015. The effect of heavy metal-induced oxidative stress on the enzymes in white rot fungus Phanerochaete chrysosporium. Applied biochemistry and biotechnology, $175,1281-1293$.

58. Zhao X., Joo J.C., Kim J.Y. 2021. Evaluation of heavy metal phytotoxicity to Helianthus annuus L. using seedling vigor index-soil model. Chemosphere, 275, 130026.

59. Zouari M., Ahmed C.B., Zorrig W., Elloumi N., Rabhi M., Delmail D., Rouina B.B., Labrousse P., Abdallah F.B. 2016. Exogenous proline mediates alleviation of cadmium stress by promoting photosynthetic activity water status and antioxidative enzymes activities of young date palm (Phoenix dactylifera L.). Ecotoxicology and environmental safety, 128, 100-108. 